\title{
CONTAGION IN ELECTRICITY MARKETS: DOES IT EXIST?
}

\author{
C. A. BOLLINO* - P. POLINORI* \\ *Department of Economics, Finance and Statistics - University of Perugia (I) \\ Via Pascoli 20, 06123, Perugia \\ Tel +39-075-585.5421 \\ Fax +39-075-585.5299 (5057) \\ E-mail:bollino@unipg.it,polpa@unipg.it
}

Jel codes: C10, C23, Q43.

Key words: Contagion; Interdependence; Identification, IPX.

\section{Overview}

This paper investigates the existence of contagion effects in electricity markets. The concept of contagion has been developed for high frequency financial markets (see the World Bank definition). Following Pick(2005) and Pesaran - Pick (2007) the paper presents a canonical, econometric model of contagion and investigates the conditions under which contagion can be distinguished from mere interdependence. The theoretical and empirical distinction between contagion and interdependence is based upon precise identification conditions, discussed in the paper. The empirical analysis is based on different regional markets in the Italian Power Exchange (IPX). This is a novel result in economic literature. The previous literature has focused much on the typical characteristics of electricity prices such as high volatility and very large, or extreme, price changes but, so far, it has ignored the question whether contagion exists among different electricity markets. The Monsoonal effects, the Tequila effect, the Asian flu, the Russian cold or the Brazilian fever are the most important types of financial crisis cited in this literature. More precisely, some researchers have focused the differences between contagion and interdependence. Pesaran - Pick (2007, p. 1247) identify three possible theories. In the first one, Monsoonal effects, financial crises appear to be contagious because underlying macroeconomic variables are correlated; in the second, spill-over effects, a crisis affects another country through external links such as trade channels, and finally in the theory of pure contagion there exist multiple equilibria and market solution jumps from a 'good' to a 'bad' equilibrium. In this paper we focus only on pure contagion relationship in the IPX at the regional level.

\section{Methods}

The analysis and identification of contagion requires that each individual market equations contains market specific regressors, consequently we have to involve market specific variables in structural equations in order to correctly specify the model. Pesaran - Pick (2007, p. 1266) show that ignoring endogeneity and interdependence can introduce a substantial upward bias in estimation of contagion coefficient. In general, problems of endogeneity requires usage of instrumental variables (IV) estimation and, in agreement with Pick (2005), we obtain consistency by including regional market specific fundamentals. Our canonical model is as follows: $y_{i t}=\alpha_{0 i}+\alpha_{i}^{\prime} x_{i t}+\beta_{i} C_{i t}+u_{i t}(1)$ where $i$ indicates markets, $t$ indicates periods, $y_{i t}$ is a electricity price index, $x_{i t}$ is a vector of predetermined variables, $\alpha_{0 \mathrm{i}}$ is a scalar parameter, $\alpha_{\mathrm{i}}$ is a vector of parameters. Contagion is addressed by including a dummy variable (Contagion Index), $C_{i t}$, in the model. Following the methodology of Favero Giavazzi (2002) and Pesaran - Pick (2007) we consider positive as well as negative extreme movements in the $y_{i t}$. Consequently the model becomes: $y_{i t}=\alpha_{0 \mathrm{i}}+\alpha_{\mathrm{i}}^{\prime} \mathrm{x}_{\mathrm{it}}+\beta_{\mathrm{i}} \mathrm{C}_{i t}^{+}+\beta_{\mathrm{i}} \mathrm{C}_{i t}^{-}+\mathrm{u}_{\mathrm{it}}(2)$ where the contagion index is $\mathrm{C}_{i t}^{+[-]}=I\left(\sum_{j=1, J \neq i}^{N} I\left(+[-] \Delta y_{j t}-c_{j}\right)\right)$ with: $\mathrm{I}(\mathrm{A})$ is indicator function and $c_{j}$ is 
endogenously estimated (with a grid search numerical procedure, between 0.5 and 2.5 standard deviations of $\Delta y_{i t}$ in order to choose the optimal size of contagion estimation. Model 2 is estimated fort each market, using the generalized instrumental variable estimation (GIVE) procedure with the lagged dependent variables of the markets $j=1,2, .(-i) \ldots, N$ used as instruments for $C^{+}{ }_{i t}$ and $C_{i t}^{-}$.

\section{Results}

Table 1 shows preliminary results:

\begin{tabular}{|c|c|c|c|c|c|c|c|c|c|c|c|c|c|c|}
\hline & \multicolumn{2}{|c|}{ NORTH } & \multicolumn{2}{|c|}{ C-NORTH } & \multicolumn{2}{|c|}{ C-SOUTH } & \multicolumn{2}{|c|}{ SOUTH } & \multicolumn{2}{|c|}{ CALABRIA } & \multicolumn{2}{|c|}{ SICILY } & \multicolumn{2}{|c|}{ SARDINIA } \\
\hline \multicolumn{15}{|c|}{ OLS } \\
\hline & Coef & S.E & Coef & S.E & Coef & S.E & Coef & S.E & Coef & S.E & Coef & S.E & Coef & S.E \\
\hline $\mathrm{C}+$ & $0.032 * * *$ & 0.005 & $0.020 * * *$ & 0.005 & $0.019 * * *$ & 0.005 & $0.020 * * *$ & 0.005 & $0.082 * * *$ & 0.006 & $0.092 * * *$ & 0.006 & $0.051 * * *$ & 0.005 \\
\hline $\mathrm{C}-$ & $0.101^{* * *}$ & 0.004 & $0.113^{* * *}$ & 0.004 & $0.113^{* * *}$ & 0.004 & $0.113^{* * *}$ & 0.004 & $0.176^{* * *}$ & 0.005 & $0.178 * * *$ & 0.005 & $0.105^{* * *}$ & 0.005 \\
\hline \multicolumn{15}{|c|}{ GIVE $m=1$} \\
\hline \multicolumn{15}{|c|}{$I V(2 S L S)$} \\
\hline & Coef & S.E & Coef & S.E & Coef & S.E & Coef & S.E & Coef & S.E & Coef & S.E & Coef & S.E \\
\hline $\mathrm{C}+$ & $-0.973 * * *$ & 0.055 & $0.211^{* * *}$ & 0.036 & -0.089 & 0.083 & -0.074 & 0.084 & $0.599 * * *$ & 0.225 & $-1.009 * * *$ & 0.130 & $-1.009 * * *$ & 0.130 \\
\hline $\mathrm{C}-$ & $-0.507 * * *$ & 0.046 & $0.079 * *$ & 0.036 & $0.157^{*}$ & 0.082 & 0.134 & 0.085 & $1.734 * * *$ & 0.131 & $-0.493^{* * *}$ & 0.105 & $-0.493 * * *$ & 0.105 \\
\hline$g$ & 5.696 & & 4.175 & & 0.817 & & 0.760 & & 0.820 & & 1.113 & & 3.385 & \\
\hline$U$-ident test ${ }^{a}$ & 571.439 & 0.000 & 419.833 & 0.000 & 82.657 & 0.867 & 76.841 & 0.9438 & 82.860 & 0.8631 & 112.532 & 0.1497 & 340.825 & 0.000 \\
\hline \multicolumn{15}{|c|}{ GMM } \\
\hline $\mathrm{C}+$ & $-0.599 * * *$ & 0.088 & $0.099^{*}$ & 0.051 & 0.017 & 0.073 & 0.021 & 0.075 & 0.148 & 0.224 & $-0.325^{* *}$ & 0.139 & $-0.568^{* * *}$ & 0.204 \\
\hline $\mathrm{C}-$ & $-0.407 * * *$ & 0.062 & $0.109^{* *}$ & 0.042 & $0.208^{* * *}$ & 0.065 & $0.163^{* *}$ & 0.067 & $0.355^{*}$ & 0.184 & $-0.243 * *$ & 0.111 & $-0.377 * *$ & 0.170 \\
\hline$g$ & 5.696 & & 4.175 & & 0.817 & & 0.760 & & 0.820 & & 1.113 & & 3.385 & \\
\hline$U$-ident test ${ }^{a}$ & 571.439 & 0.000 & 419.833 & 0.000 & 82.657 & 0.867 & 76.841 & 0.9438 & 82.860 & 0.8631 & 112.532 & 0.1497 & 340.825 & 0.000 \\
\hline \multicolumn{15}{|c|}{ GIVE $\mathrm{m}=3$} \\
\hline \multicolumn{15}{|c|}{$I V(2 S L S)$} \\
\hline & Coef & S.E & Coef & S.E & Coef & S.E & Coef & S.E & Coef & S.E & Coef & S.E & Coef & S.E \\
\hline $\mathrm{C}+$ & $-1.280^{* * *}$ & 0.072 & $0.177 * * *$ & 0.004 & -0.070 & 0.075 & 0.085 & 0.076 & $0.888^{* * *}$ & 0.104 & $0.769^{* * *}$ & 0.124 & $-2.298^{\star \star \star}$ & 0.194 \\
\hline C- & $-0.875^{* * *}$ & 0.069 & $0.107 * * *$ & 0.003 & $0.101 * * *$ & 0.004 & 0.1913 & 0.201 & $2.054 * * *$ & 0.217 & $-0.786^{* * *}$ & 0.202 & $-2.050^{\star \star \star}$ & 0.217 \\
\hline$g$ & 4.331 & & 10.106 & & 4.405 & & 1.222 & & 1.902 & & 4.175 & & 5.696 & \\
\hline$U_{\text {-ident test }}{ }^{a}$ & 443.982 & 0.000 & 530.99 & 0.000 & 984.79 & 0.000 & 275.927 & 0.000 & 192.617 & 0.000 & 419.833 & 0.000 & 571.439 & 0.000 \\
\hline \multicolumn{15}{|c|}{ GMM } \\
\hline $\mathrm{C}+$ & $-0.772 * * *$ & 0.119 & 0.085 & 0.140 & $0.141^{* *}$ & 0.069 & 0.018 & 0.077 & 0.101 & 0.283 & $0.219 * * *$ & 0.071 & $-0.450^{\star \star \star}$ & 0.021 \\
\hline C- & $-0.543 * * *$ & 0.103 & $0.155^{* * *}$ & 0.085 & $0.218^{* * *}$ & 0.006 & $0.171^{* *}$ & 0.086 & $0.312^{*}$ & 0.136 & $-0.286^{* * *}$ & 0.069 & $-0.305^{\star \star *}$ & 0.072 \\
\hline$g^{b}$ & 4.331 & & 10.106 & & 4.405 & & 1.222 & & 1.902 & & 4.175 & & 5.696 & \\
\hline$U$-ident test ${ }^{a}$ & 443.982 & 0.000 & 530.99 & 0.000 & 984.79 & 0.000 & 275.927 & 0.000 & 192.617 & 0.000 & 419.833 & 0.000 & 571.439 & 0.000 \\
\hline
\end{tabular}

The coefficient signs are as expected and confirm that the contagion effect are statically significant in most markets and that IV estimations show that OLS are biased.

\section{Conclusions}

The most important conclusions of this paper are that contagion can be identified separately from interdependence and that effects are asymmetric. In IPX there occurs contagion effects which can be identified with statistically significant coefficients. Moreover, we find that, most likely, price crisis occur when dynamic patterns are spiking suddenly downward and not upward. This is consistent with theoretical prediction, that sudden equilibrium change occurs when a collusive behavior breaks down, resulting in a competitive behavior. Finally, this indicates that interdependence occurs when price dynamic patterns are moving upward.

\section{References}

Favero C.A., Giavazzi F. (2002), Is the international propagation of financial shocks non-linear? Evidence from the ERM, in: Journal of International Economics, 57, pp. 231-246.

Pick A. (2005), Estimating contagion via instrumental variables, mimeo, http://www.riskturk.com/ec2/submitted/cec ec2.pdf [Download 14-01-2008]

Pesaran M.H., Pick A. (2007), Econometric issues in the analysis of contagion, in: Journal of Economic Dynamics \& Control, 31, pp. 1245-1277. 